\title{
Die Elemente
}

\section{der \\ nächsten Zukunft der Medicin,}

\author{
entwickelt
}

aus der Vergangenheit und Gegenwart.

E i n B l i c k

von

\section{Heinrich Damerow, \\ Dr. der Medicin und Chirurgie, Privatdncent an der Köniğl. \\ Friedrich - Wilhelms - Universität zu Berlin.}

$$
\begin{aligned}
& \text { Berlin, } 1829 . \\
& \text { Gedruckt und ver tegt } \\
& \text { bei G. lieiner. }
\end{aligned}
$$


